\title{
Management of tachycardia
}

\section{Rakesh Gopinathannair, $\mathrm{MD}, \mathrm{MA}^{1 *}$ and Brian Olshansky, $\mathrm{MD}^{2}$}

\author{
Addresses: ${ }^{1}$ Division of Cardiovascular Medicine, University of Louisville School of Medicine, ACB/A3L41, 550 So. Jackson St., Louisville, KY, USA; \\ ${ }^{2}$ University of Iowa Hospitals and Clinics, 200 Hawkins Dr, Iowa City, IA, USA \\ *Corresponding author: Rakesh Gopinathannair (rakesh.gopinathannair@louisville.edu) \\ Fl000Prime Reports 2015, 7:60 (doi:10.12703/P7-60) \\ All FI000Prime Reports articles are distributed under the terms of the Creative Commons Attribution-Non Commercial License \\ (http://creativecommons.org/licenses/by-nc/3.0/legalcode), which permits non-commercial use, distribution, and reproduction in any medium, \\ provided the original work is properly cited. \\ The electronic version of this article is the complete one and can be found at: http://f1000.com/prime/reports/m/7/60
}

\begin{abstract}
Tachycardia, conventionally, but arbitrarily, defined as an atrial and/or ventricular rate of $>100$ beats per minute, is encountered commonly and can be physiological or pathological in origin. Various adverse consequences from tachycardia have been recognized, and an important one is the association between persistent tachycardia and cardiomyopathy. In this article, we provide an up-to-date review on the etiology of tachycardia, management strategies, and the prognosis of patients presenting with tachycardia and cardiomyopathy.
\end{abstract}

\section{Introduction}

Heart rate, perhaps the most commonly measured vital sign in clinical practice, is a key determinant of myocardial metabolism and cardiac output [1]. Tachycardia, conventionally defined as an atrial and/or ventricular rate of $>100$ beats per minute (bpm) has an arbitrary and debated definition [2,3]. Nevertheless, tachycardia can be of importance, since it can cause myocardial ischemia, hypotension, low cardiac output, peripheral hypoperfusion, severe symptoms (chest pain, weakness, syncope, lightheadedness), cardiomyopathy, cardiac arrest and death.

Tachycardias can be broadly classified as: sinus tachycardia (appropriate physiologically and inappropriate); postural orthostatic tachycardia syndrome (POTS); supraventricular tachycardia (atrial tachycardia, AV nodal reentrant tachycardia and AV reentrant tachycardia); atrial flutter with rapid ventricular response; atrial fibrillation with rapid ventricular response; junctional tachycardia; or ventricular tachycardia.

\section{When is tachycardia a problem?}

Sinus tachycardia (heart rate $>100 \mathrm{bpm}$ ) is the form encountered most commonly in clinical practice. The vast majority of sinus tachycardia is physiological and associated with catecholaminergic triggers (e.g. emotions, physical activity, and other stresses). The evaluation and management of persistent sinus tachycardia involves careful assessment of whether tachycardia is an appropriate response or not, the discussion of which is beyond the scope of this manuscript.

A small percentage of patients can have persistent sinus tachycardia without any underlying illness or structural heart disease, and are classified as having inappropriate sinus tachycardia $[4,5]$. Inappropriate sinus tachycardia is under-recognized, can be associated with debilitating symptoms and poses significant management challenges. Postural orthostatic tachycardia syndrome (POTS), a neurally-mediated disorder (defined as orthostatic tachycardia of $>30$ beats from baseline or a heart rate $>120 \mathrm{bpm}$ with no significant blood pressure changes), can be associated with significant symptoms. Supraventricular tachycardia (i.e. tachycardia requiring tissue above the His bundle to perpetuate) can be associated with severe symptoms, but is rarely lifethreatening. Atrial fibrillation and atrial flutter may be associated with rapid ventricular rates. Ventricular tachyarrhythmias can be idiopathic (in the setting of a structurally normal heart) to life-threatening (in the setting of structural heart disease including cardiomyopathy). Ventricular tachycardia can be monomorphic or polymorphic, sustained or non-sustained. 


\section{Tachycardia-mediated cardiomyopathy}

Persistent tachycardia of any form can cause tachycardiamediated cardiomyopathy (TMC), can precipitate heart failure and can result in death [6]. If TMC is the direct consequence of tachycardia, it is referred to as tachycardiainduced cardiomyopathy or "pure" TMC [7]. Tachycardia can also worsen pre-existing cardiomyopathy ("impure" $\mathrm{TMC}$ ). TMC is partially or completely reversible, when measured by heart failure symptoms and left ventricular ejection fraction, once the culprit tachycardia is treated adequately.

\section{Tachycardias causing cardiomyopathy}

Any persistent tachycardia (Table 1) can result in TMC. Atrial fibrillation with persistent rapid ventricular rates is the most common cause $[6,8]$. Sinus tachycardia and POTS are usually not associated with TMC for unclear reasons. Thyrotoxicosis resulting in persistent sinus tachycardia or atrial fibrillation and consequent high output heart failure does not usually cause TMC [9].

\section{Management of a patient with tachycardia and cardiomyopathy}

The primary management strategy in TMC is focused on aggressive attempts to control tachycardia with the aim of improving heart failure symptoms and reversing left ventricular dysfunction [6]. Depending on the clinical condition of the patient and type of tachycardia, rate control and/or rhythm control strategies are usually employed. Underlying disease conditions, if present, should be optimized as much as possible and as soon as possible.

If successful rate control or tachycardia elimination can reverse heart failure symptoms and cardiomyopathy, TMC is confirmed [8]. In patients with TMC, standard heart failure therapy (beta-blockers, angiotensinconverting enzyme inhibitors, and spironolactone) can

Table I. Arrhythmias responsible for tachycardia-mediated cardiomyopathy

\begin{tabular}{l}
\hline Supraventricular \\
Atrial fibrillation \\
Atrial flutter \\
Atrial tachycardia \\
AV nodal reentrant tachycardia \\
AV reentrant tachycardia \\
Permanent junctional reciprocating tachycardia (PJRT) \\
Ventricular \\
Idiopathic ventricular tachycardia \\
Fascicular tachycardia (left septal ventricular tachycardia) \\
Ectopy \\
Frequent premature ventricular contractions \\
Frequent premature atrial contractions \\
Pacing \\
High-rate atrial pacing \\
Persistent rapid ventricular pacing \\
\hline
\end{tabular}

attenuate neurohumoral response and affect favorable remodeling [6].

Rate control is commonly employed to manage atrial fibrillation causing TMC. Beta-blockers, calcium-channel antagonists and/or digoxin are commonly utilized for rate control. The optimal rate control strategy in TMC is yet to be identified, although a combination of drugs is often needed for adequate rate control; a beta-blocker combined with digoxin may have superior benefits $[10,11]$.

The requirements for adequate rate control in TMC remain uncertain. In permanent atrial fibrillation, lenient rate control (resting ventricular rate $<110 \mathrm{bpm}$ ) has been shown to have similar short-term outcomes to a strict rate control approach (resting heart rate $<80 \mathrm{bpm}$ and exercise heart rate $<110 \mathrm{bpm}$ ). Whether a lenient approach to rate control applies to patients at risk of developing TMC is unlikely but requires further evaluation [12]. In patients with atrial fibrillation-mediated $\mathrm{TMC}$, who are difficult to rate control and in whom a rhythm control strategy is not feasible or desired, AV node ablation with pacemaker implantation provides an effective means of rate control [13]. Recent data, however, arguably point to a cardiac resynchronization therapy (CRT) pacing approach [14].

Although rate control is important in atrial fibrillationmediated TMC, rhythm control may be important as well, as irregularity of the rhythm may also result in development of cardiomyopathy and heart failure [15]. Further 'rate control' in atrial fibrillation may be a misnomer, as the rate is never exactly as it would be in sinus rhythm. Rhythm control strategies involve chronic or intermittent use of antiarrhythmic drugs, pharmacological or electrical cardioversion, and catheter ablation. A hemodynamically unstable patient with atrial fibrillation and rapid ventricular rates often needs emergent cardioversion. Elective external cardioversion can be performed safely in an outpatient setting with minimal complications [16]. Intravenous ibutilide, a class III antiarrhythmic drug, can be effective for pharmacological cardioversion. The dose is $1 \mathrm{mg}$ over 10 minutes, but carries a risk of QT prolongation and polymorphic ventricular tachycardia, and therefore requires several hours of telemetry monitoring following the dose [17]. Vernakalant, an atriumspecific K+ channel blocker, has been shown to be effective in restoring sinus rhythm, may not affect QT prolongation as much, and can be a safer option [18]. However, vernakalant is not approved for use in the US.

It is critical in TMC patients to maintain sinus rhythm in the long-term. Antiarrhythmic drugs and catheter ablation are commonly employed strategies. Amiodarone, which 
blocks multiple cardiac ion channels, is most commonly used for this purpose and is superior to sotalol, another class III antiarrhythmic drug $[19,20]$. However, long-term use of amiodarone has the potential for extracardiac toxicity (hypo- and hyperthyroidism, abnormal liver enzymes, neuropathy, dermatitis, optic neuritis, and interstitial lung disease). Close follow-up of thyroid and liver function every 6 months should be performed [20].

An underutilized, but highly effective, drug is dofetilide, a pure class III antiarrhythmic drug with no betablocking properties (unlike sotalol) [21]. No head-tohead comparison has been undertaken with amiodarone but, when used properly and with careful monitoring, this drug can be quite effective in maintaining sinus rhythm without substantial risk for QT prolongation and torsade de pointes. Dofetilide requires initiation in the hospital with strict electrocardiographic supervision. Dosing depends on the initial QTc, renal function and concomitant QT-prolonging drugs [21].

Catheter ablation has emerged as a promising therapy to maintain sinus rhythm in patients with both paroxysmal and persistent atrial fibrillation. In patients with atrial fibrillation and heart failure, catheter ablation of atrial fibrillation can improve quality of life and left ventricular function [22]. In a systematic review of the efficacy of catheter ablation in atrial fibrillation patients with concomitant left ventricular dysfunction, sinus rhythm was maintained in $57 \%$ of patients following a single procedure. The success rate increased to $82 \%$ with more than one procedure and/or use of antiarrhythmic drug therapy. The mean increase in left ventricular ejection fraction was $13.3 \%$, suggesting effectiveness of catheter ablation in this TMC population [23].

Whether or not rhythm control is superior to rate control in TMC patients with atrial fibrillation is not fully established. Large randomized studies of atrial fibrillation patients (AF-CHF, AFFIRM) have shown that rate control was equivalent to rhythm control for hard clinical endpoints for the patients who were selected to be enrolled [24,25]. However, it is likely that the pathophysiology of atrial fibrillation-mediated TMC varies in the patient population studied in these trials, and these results may not apply to TMC patients. Moreover, these studies compared rate control to antiarrhythmic drugs, mostly amiodarone, and the toxicity of antiarrhythmic drugs may offset benefits gained from maintaining sinus rhythm [26]. In the real world, achieving and monitoring rate control is a challenge in the cardiomyopathy patient. In patients with drug-refractory atrial fibrillation and heart failure, pulmonary vein isolation has been shown to have better outcomes than AV node ablation and CRT pacing, suggesting the superiority of rhythm control [27]. A recent randomized trial (AATAC-AF) compared catheter ablation with amiodarone for rhythm control of persistent atrial fibrillation in patients with heart failure and cardiomyopathy. A total of 203 patients were followed for 24 months and catheter ablation was shown to be far superior to amiodarone in freedom from atrial fibrillation (70\% in the ablation arm $v$ s. $34 \%$ in the amiodarone arm), quality of life, hospitalization rate, and mortality. Left ventricular ejection fraction improved $9.6 \pm 7.4 \%$ in the ablation arm vs. $4.2 \pm 6.2 \%$ in the amiodarone arm $(P<0.01)$ (NCT00729911).

For atrial flutter and supraventricular tachycardias (atrial tachycardia, AV nodal reentry tachycardia, AV reentrant tachycardias, permanent junctional reciprocating tachycardia), a curative strategy by catheter ablation should be pursued whenever possible with a goal of complete elimination of the tachycardia. Success rates are high. Similarly, early use of catheter ablation should be employed for TMC due to idiopathic ventricular tachycardias and/or frequent ventricular premature beats, as it can achieve a complete cure [28].

In summary, our management approach for patients with suspected TMC is to pursue an aggressive rhythm control strategy whenever possible, with the goal of restoring and maintaining sinus rhythm. Aggressive rate control should be pursued in situations where rhythm control is not feasible or desired. Concomitant heart failure therapy with angiotensin-converting enzyme inhibitors and beta-blockers adds value.

\section{Recovery and prognosis of TMC}

Once pathologic tachycardia is controlled or eliminated, gradual recovery in left ventricular function and heart failure symptoms is the rule in a patient with TMC. Most "pure" TMC patients are expected to recover within 3-6 months after tachycardia suppression. However, only limited long-term data are available for these patients. A major factor affecting prognosis is tachycardia recurrence. In a study of 24 patients with TMC and heart failure, 5 patients had recurrent tachycardia after recovery in left ventricular function and all had rapid decline in ventricular function within 6 months of recurrence[29], suggesting that structural abnormalities at the ultrastructural level persist despite tachycardia resolution [30]. Thus, careful follow-up and monitoring for arrhythmia recurrence is necessary for these patients. Sudden death has been reported in TMC patients even after recovery in ventricular function [29], highlighting the fact that tachycardia should be controlled before cardiomyopathy ensues. 


\section{Conclusions}

Tachycardia, a common problem in clinical practice, can be secondary to physiological and/or pathological causes. One major adverse consequence of pathological tachycardia is development of cardiomyopathy with subsequent heart failure. Early recognition is important, and an aggressive approach towards rate and rhythm control of the culprit tachycardia can result in resolution of symptoms and partial or complete recovery of left ventricular function. Concomitant heart failure therapy to aid favorable remodeling is recommended. Close surveillance for arrhythmia recurrence during follow-up is warranted to avoid further decline in ventricular function.

\section{Abbreviations}

bpm, beats per minute; CRT, cardiac resynchronization therapy; POTS, postural orthostatic tachycardia syndrome; TMC, tachycardia-mediated cardiomyopathy.

\section{Disclosures}

Dr. Rakesh Gopinathannair is a consultant for St. Jude Medical and Abiomed, and a member of the Speaker's Bureau at Pfizer/BMS. Dr. Brian Olshansky is a consultant at Boston Scientific, Medtronic, Daichi Sankyo, Biotronik, Cardionomics, BioControl, Amarin, Boehringer Ingelheim, and On-X.

\section{References}

I. Braunwald E: Control of myocardial oxygen consumption: physiologic and clinical considerations. Am J Cardiol 197I, 27:416-32.

2. Gopinathannair R, Sullivan RM, Olshansky B: Slower heart rates for healthy hearts: time to redefine tachycardia? Circ Arrythm Electrophysiol 2008, I:321-3.

3. Palatini $P$ : Need for a revision of the normal limits of resting heart rate. Hypertension 1999, 33:622-5.

4. Olshansky B, Sullivan RM: Inappropriate sinus tachycardia. J Am Coll Cardiol 2013, 61:793-801.

5. Hottigoudar RU, Gopinathannair R: 'Inappropriate' sinus tachycardia: does the 100 beats per min cut-off matter? Future Cardiol 2013, 9:273-88.

6. Gopinathannair R, Sullivan R, Olshansky B: Tachycardia-mediated cardiomyopathy: recognition and management. Current Heart Fail Rep 2009, 6:257-64.

7. Fenelon G, Wijns W, Andries E, Brugada P: Tachycardiomyopathy: mechanisms and clinical implications. Pacing Clin Electrophysiol 1996, 19:95-106.

8. Calò L, Ruvo E de, Sette A, Sciarra L, Scioli R, Sebastiani F, Topai M, lulianella R, Navone G, Lioy E, Gaita F: Tachycardia-induced cardiomyopathy: mechanisms of heart failure and clinical implications. J Cardiovasc Med (Hagerstown) 2007, 8: I 38-43.

9. Biondi B: Mechanisms in endocrinology: Heart failure and thyroid dysfunction. Eur J Endocrinol 2012, 167:609-18.

\section{FlOOOPrime} RECOMMENDED

10. Farshi R, Kistner D, Sarma JS, Longmate JA, Singh BN: Ventricular rate control in chronic atrial fibrillation during daily activity and programmed exercise: a crossover open-label study of five drug regimens. J Am Coll Cardiol 1999, 33:304-I0.

FIOOOPrime
RECOMMENDED

II. Olshansky B, Rosenfeld LE, Warner AL, Solomon AJ, O'Neill G, Sharma A, Platia E, Feld GK, Akiyama T, Brodsky MA, Greene HL: The Atrial Fibrillation Follow-up Investigation of Rhythm Management (AFFIRM) study: approaches to control rate in atrial fibrillation. J Am Coll Cardiol 2004, 43: I20I-8.

12. Van Gelder Isabelle C, Groenveld HF, Crijns Harry J G M, Tuininga YS, Tijssen Jan G P, Alings AM, Hillege HL, Bergsma-Kadijk JA, Cornel JH, Kamp O, Tukkie R, Bosker HA, Van Veldhuisen Dirk J, Van den Berg Maarten $P$ : Lenient versus strict rate control in patients with atrial fibrillation. $N$ Engl J Med 2010, 362:1363-73.

\section{FlOOOPrime}

13. Narasimhan C, Blanck Z, Akhtar M: Atrioventricular nodal modification and atrioventricular junctional ablation for control of ventricular rate in atrial fibrillation. J Cardiovasc Electrophysiol 1998, 9:SI46-50.

14. Curtis AB, Worley SJ, Adamson PB, Chung ES, Niazi I, Sherfesee L, Shinn T, Sutton MS: Biventricular pacing for atrioventricular block and systolic dysfunction. N Engl J Med 20I3, 368:I585-93.

\section{FlOOOPrime
RECOMMENDED}

15. Nedios S, Sommer P, Dagres N, Kosiuk J, Arya A, Richter S, Gaspar T, Kanagkinis N, Dinov B, Piorkowski C, Bollmann A, Hindricks G, Rolf S: Long-term follow-up after atrial fibrillation ablation in patients with impaired left ventricular systolic function: the importance of rhythm and rate control. Heart Rhythm 2014, I I:344-5I.

\section{FIOOOPrime
RECOMMENDED}

16. Botkin SB, Dhanekula LS, Olshansky B: Outpatient cardioversion of atrial arrhythmias: efficacy, safety, and costs. Am Heart J 2003, | 45:233-8.

17. Fragakis N, Papadopoulos N, Papanastasiou S, Kozirakis M, Maligkos G, Tsaritsaniotis E, Katsaris G: Efficacy and safety of ibutilide for cardioversion of atrial flutter and fibrillation in patients receiving amiodarone or propafenone. Pacing Clin Electrophysiol 2005, 28:954-6I.

\section{FlOOOPrime}

RECOMMENDED

18. Camm AJ, Capucci A, Hohnloser SH, Torp-Pedersen C, Van Gelder Isabelle C, Mangal B, Beatch G: A randomized activecontrolled study comparing the efficacy and safety of vernakalant to amiodarone in recent-onset atrial fibrillation. J Am Coll Cardiol 20II, 57:313-2I.

FlOOOPrime
RECOMMENDED

19. Singh BN, Singh SN, Reda DJ, Tang XC, Lopez B, Harris CL, Fletcher RD, Sharma SC, Atwood JE, Jacobson AK, Lewis HD, Raisch DW, Ezekowitz MD: Amiodarone versus sotalol for atrial fibrillation. N Engl J Med 2005, 352:186I-72.

\section{FlOOOPrime \\ RECOMMENDED}

20. Olshansky B, Sami M, Rubin A, Kostis J, Shorofsky S, Slee A, Greene HL: Use of amiodarone for atrial fibrillation in patients with preexisting pulmonary disease in the AFFIRM study. Am J Cardiol 2005, 95:404-5.

21. Banchs JE, Wolbrette DL, Samii SM, Penny-Peterson ED, Patel PP, Young SK, Gonzalez MD, Naccarelli GV: Efficacy and safety of dofetilide in patients with atrial fibrillation and atrial flutter. J Interv Card Electrophysiol 2008, 23: I I I-5.

\section{FlOOOPrime} RECOMMENDED

22. Hsu L, Jaïs P, Sanders P, Garrigue S, Hocini M, Sacher F, Takahashi $Y$, Rotter M, Pasquié J, Scavée C, Bordachar P, Clémenty J, 
Haïssaguerre M: Catheter ablation for atrial fibrillation in congestive heart failure. N Engl J Med 2004, 35 I:2373-83.

23. Ganesan AN, Nandal S, Lüker J, Pathak RK, Mahajan R, Twomey D, Lau DH, Sanders P: Catheter ablation of atrial fibrillation in patients with concomitant left ventricular impairment: a systematic review of efficacy and effect on ejection fraction. Heart Lung Circ 2015, 24:270-80.

\section{FlOOOPrime} RECOMMENDED

24. Roy D, Talajic M, Nattel S, Wyse DG, Dorian P, Lee KL, Bourassa MG, Arnold J Malcolm O, Buxton AE, Camm AJ, Connolly SJ, Dubuc M, Ducharme A, Guerra PG, Hohnloser SH, Lambert J, Le Heuzey J, O'Hara G, Pedersen OD, Rouleau J, Singh BN, Stevenson LW, Stevenson WG, Thibault B, Waldo AL: Rhythm control versus rate control for atrial fibrillation and heart failure. $N$ Engl J Med 2008, 358:2667-77.

\section{FlOOOPrime

RECOMMENDED

25. Wyse DG, Waldo AL, DiMarco JP, Domanski MJ, Rosenberg Y, Schron EB, Kellen JC, Greene HL, Mickel MC, Dalquist JE, Corley SD: A comparison of rate control and rhythm control in patients with atrial fibrillation. N Engl J Med 2002, 347:1825-33.

\section{FlOOOPrime}

RECOMMENDED

26. Corley SD, Epstein AE, DiMarco JP, Domanski MJ, Geller N, Greene HL, Josephson RA, Kellen JC, Klein RC, Krahn AD, Mickel M, Mitchell LB, Nelson JD, Rosenberg Y, Schron E, Shemanski L, Waldo AL, Wyse DG: Relationships between sinus rhythm, treatment, and survival in the Atrial Fibrillation
Follow-Up Investigation of Rhythm Management (AFFIRM) Study. Circulation 2004, 109:1509-13.

FlOOOPrime
RECOMMENDED

27. Khan MN, Jaïs $P$, Cummings J, Di Biase L, Sanders $P$, Martin DO, Kautzner J, Hao S, Themistoclakis S, Fanelli R, Potenza D, Massaro R, Wazni O, Schweikert R, Saliba W, Wang P, Al-Ahmad A, Beheiry S, Santarelli P, Starling RC, Dello Russo A, Pelargonio G, Brachmann J, Schibgilla V, Bonso A, Casella M, Raviele A, Haïssaguerre M, Natale A: Pulmonary-vein isolation for atrial fibrillation in patients with heart failure. N Engl ] Med 2008, 359: 1778-85.

\section{FlOOOPrime}

RECOMMENDED

28. Bogun F, Crawford T, Reich S, Koelling TM, Armstrong W, Good E, Jongnarangsin K, Marine JE, Chugh A, Pelosi F, Oral H, Morady F: Radiofrequency ablation of frequent, idiopathic premature ventricular complexes: comparison with a control group without intervention. Heart Rhythm 2007, 4:863-7.

\section{FlOOOPrime}

RECOMMENDED

29. Nerheim P, Birger-Botkin S, Piracha L, Olshansky B: Heart failure and sudden death in patients with tachycardia-induced cardiomyopathy and recurrent tachycardia. Circulation 2004, I I 0:247-52.

30. Ling L, Kalman JM, Ellims AH, lles LM, Medi C, Sherratt C, Kaye DM, Hare JL, Kistler PM, Taylor AJ: Diffuse ventricular fibrosis is a late outcome of tachycardia-mediated cardiomyopathy after successful ablation. Circulation. Arrhythmia Electrophysiol 2013, 6:697-704. 